\title{
Influence of the main operational factors on the working capacity of a mining hydraulic excavator
}

\author{
Abdelwahab Agaguena, Danila Chishegorov, Sergey Ivanov and Alexander Mikhailov
}

Saint-Petersburg Mining University, Department of mechanical engineering, 21st Line V.O., 2, 199106, Saint-Petersburg, Russian Federation

\begin{abstract}
The analysis of factors influencing the failures of a mining excavator is substantiated. The classification of factors and methods of dealing with them will have a great importance in mining engineering. The article considers an example of the influence of various factors on the lifting mechanism of a hydraulic mining excavator. Thanks to the early identification of the most influencing factors on a mining excavator, it will be possible to manage the equipment maintenance and repair under actual conditions and operating conditions.
\end{abstract}

\section{Introduction}

The increase in the volume of development of solid minerals by the open method depends on the efficiency of functioning of hydraulic excavators widely used in modern cyclical and cyclical-flow complexes. Currently, the open-cut method for the development of mineral deposits is a priority in the mining industry in Russia [1].

The global trend shows that at mining enterprises the use of mechanical rope shovels is decreasing in favor of more actively developing new types of excavation loaders - powerful hydraulic excavators - forward and reverse shovels [2].

Hydraulic excavators are the main mining unit in open pit mines (coal, iron ore, peat etc.) [3]. Large mining enterprises, in search of cost reduction and increasing production volumes, are showing interest in large single-capacity excavators. At the same time, the volume of mining operations is proportional to the number of excavator fleet, and the degree of this proportionality directly depends on their reliability and is determined by the amount of equipment downtime.

\section{Objective}

The purpose of this work is to identify the regularities of the process of resource development by a mining hydraulic excavator from natural-man-made, organizational and technical factors and repair and restoration impact, for the development of scientifically based technical and technological solutions to effectively maintain the excavator in a state of readiness, which is important for the mining industry.

\section{Materials and methods}

The resource of open pit excavators is influenced by weather and climatic, mining and geological and organizational and technical factors. The service life of a mining excavator depends on the level of technical service provided at a particular enterprise, as well as on compliance with the rules for the technical operation of machines [4].

Mining machines, as you know, operate in very difficult conditions associated, in addition to weather, with mining and geological conditions of occurrence of the mineral, as well as climatic conditions and high dynamics of the acting loads during the operation of the mining machine [5].

\section{Results}

The main source influencing the resource of a mining excavator is the process of interaction of their executive bodies with the destructible mass or transported material [6].

A high level of unscheduled downtime of excavators leads to significant material costs, both due to a decrease in the extraction of minerals and because of the high cost of repairing large-sized units and metal structures [14].

The resource of the excavator is influenced by a significant number of factors; each of them affects the resource of the excavator in a different way [8].

The most significant of them, leading to the intensification of degradation processes: equipment age $\left(K_{d}=1.02-1.90\right)$, mining and geological factors $\left(K_{d}=\right.$ $1.1-1.5)$, weather and climatic $\left(K_{d}=1.01-1.11\right)$, quality of face preparation $\left(K_{d}=1.02-1.21\right)$, excavator control $\left(K_{d}=1.2-1.9\right)$, organizational $\left(K_{d}=1.18-1.46\right)$, technical strategy maintenance $\left(K_{d}=0.89-1.13\right)$. Here $K_{d}$ is the

\footnotetext{
* Corresponding author: wahabtounssi40@gmail.com
} 
coefficient of degradation processes, defined as the ratio of the operating time with varying the influencing factor to the nominal values under normal operating conditions [9].

The development of desert mineral deposits sets the task of further improving the reliability and quality of the work of quarry equipment. This dictates a constant increase in strength and complexity of machine design and operation in harsh conditions with prolonged exposure to high temperatures. At the same time, the severity of the weather and climatic conditions of operation impose special requirements on both the design of the machines and the construction and operational materials.

However, as the operating experience shows, with an unchanged fleet of mining equipment, their productivity is steadily decreasing. The main reasons for this are the complexity of operating conditions, an increase in the depth of open drilling, physical and moral aging of machines, shortcomings in the organization of mining, maintenance and repair, which leads to a significant decrease in reliability indicators. First of all, this refers to the indicators of climatic reliability, which are determined by the intensity of climatic factors.

A significant influence on the performance of mining excavators is exerted by weather and climatic conditions, which are characterized by an amplitude of air temperature change from -55 to $+30^{\circ} \mathrm{C}$ with daily fluctuations up to $25^{\circ} \mathrm{C}[11,18]$.

Currently, the problem of climatic reliability is most often solved through the use of materials that increase the durability of parts and assemblies, and the adaptation of the machine structure to maintenance and repair [10].

Fig. 2 shows a graphical illustration of the dependence of the influence of weather and climatic conditions on the complexity of the current repair of mining machines.

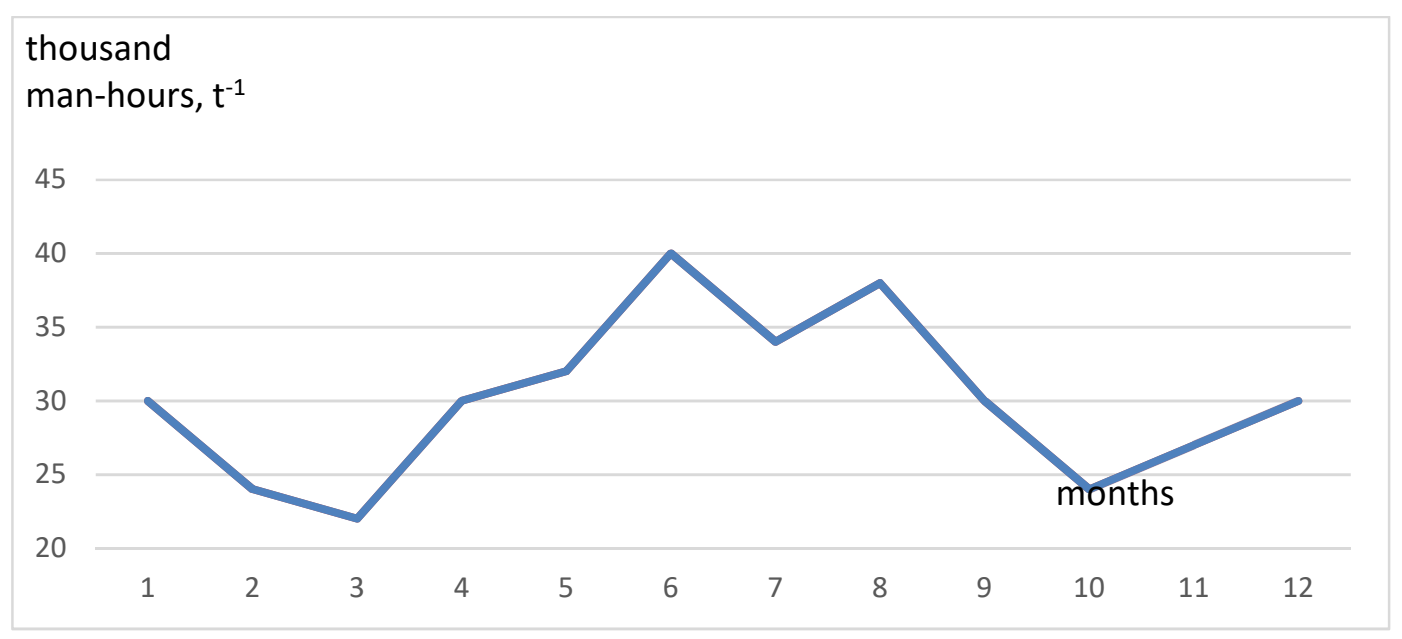

Fig. 1. The graph of the dependence of the influence of weather and climatic conditions on the labour intensity of current repairs of mining machines [5].

From the analysis of the graphs, it can be seen that the growth of training is more intensive among highly qualified performers than among low-skilled performers, and specialization in repair work leads to the intensification of operations during the maintenance and repair of equipment.

Industrial dust is a dangerous and harmful production factor. Dust can have a fibrous effect on the human body (the effect of dust, since connective tissue grows in the lungs, disrupting the normal structure and functions of the organ), toxic and irritating. In addition, dust from certain minerals can form explosive concentrations in mine air [12].

The ingress of dust into the atmosphere of open pits is due not only to the natural volumes of the extracted rock mass, but also to a large extent to the unit capacity of the mining equipment. The greatest dustiness of the air occurs during the loading and transportation of ore. The basis of man-made emissions during the extraction of iron ore is iron silicate dust.

The smallest dust particles affect the equipment:

- abrasive;
- heat-insulating;

- concentrating fine fractions on the surface.

When operating mining equipment in a dusty environment, the following occurs:

- increased wear of moving parts of mechanisms due to the abrasive action of dust particles;

- contamination of lubricants and hydraulic fluids;

- overheating of units and assemblies due to the deposition of a dust layer;

- clogged engine air filters;

- malfunction of high-precision equipment microcircuits.

Equipment operation under dynamic dust flows in the Sahara Desert (sandstorms, dry winds, etc.) also leads to abrasive damage to external parts, especially excavator hydraulic cylinder rods.

Operation of equipment in a dusty environment, where air circulation is weak, leads to the appearance of a static layer of dust on the surface of the machines, which prevents air and heat exchange.

Exterior cleaning of cars in the desert has to be done frequently. This process is very tedious. Machines are 
washed before the next maintenance, before shipment or preparation for repair, and immediately before disassembly during repair. For external cleaning of machines, jet cleaning is mainly used.

At the same time, timely maintenance and repair by qualified personnel according to the documents of a correctly drawn up normative repair base is able to maintain the corresponding systems in working order.

Let us consider, using the example of the PC-3000 mining hydraulic excavator, the effect of four types of downtime, namely: weather, organizational and technological, unscheduled and downtime for maintenance and repair. The total downtime of the excavator is about $20 \%$ of the annual working time fund. The structure of the downtime itself is shown in Fig. 2. The largest volume of downtime is associated with emergency shutdowns (39\%), maintenance and repair $(43 \%)$, organizational and technological downtime is $17 \%$ and downtime associated with adverse weather conditions is $1 \%$.

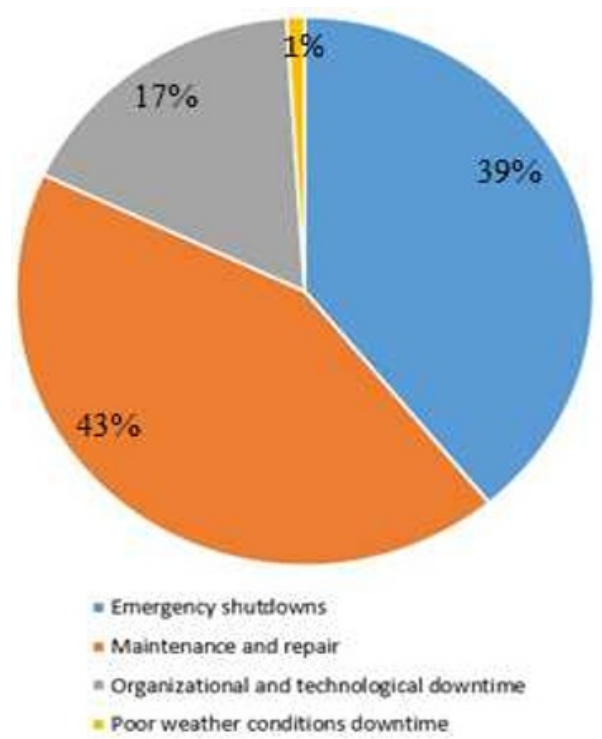

Fig. 2. Reasons for downtime of mining excavators [4]

As practice shows, as the total operating time of mining machines increases, the equipment failure rate increases, which entails an increase in the time to eliminate the consequences of equipment failures and, as a consequence, a decrease in the amount of excavator output [13].

Analysis of the contribution of mechanical and electrical subsystems of excavators to the total number of failures in Fig. 3 shows that in most cases failures of mechanical equipment prevail and account for $50-70 \%$ of their total number [7].

The most loaded is the drive of the mining excavator lifting mechanism. The hoist gearbox is most susceptible to wear, since $100 \%$ of the working time is under load.

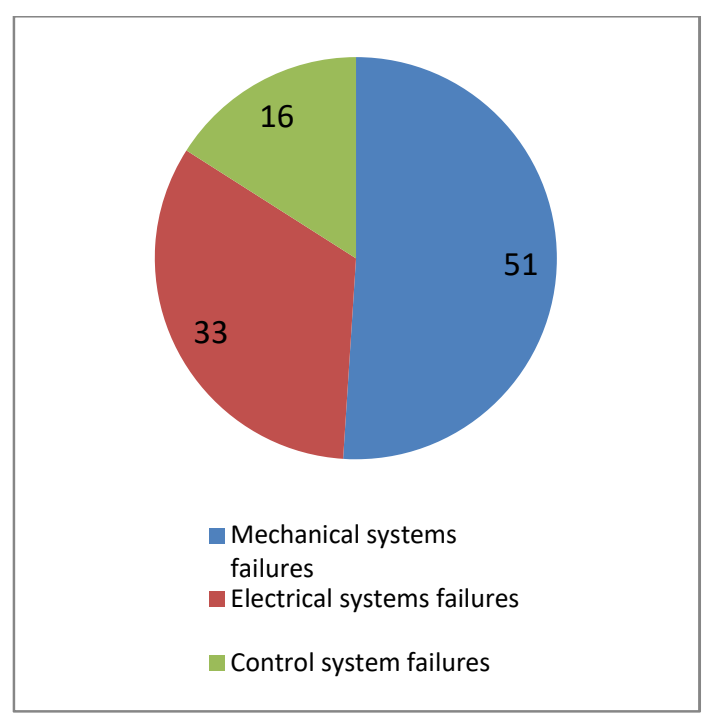

Fig. 3. Distribution of excavator equipment failures [7]

In the process of destruction of rocks in the digging zone, intense dust formation occurs. Despite the dust suppression measures taken, the smallest dust particles penetrate into these interfaces, and then into the lubrication of the gearboxes.

The following types of wear are most typical of gearboxes of mining machines: adhesive, abrasive, fatigue, when seizing, oxidative.

Let us analyze the downtime of the mining excavator for a year. As can be seen from Fig. 4, the largest downtime is associated with the repair of mechanical equipment, namely $80 \%$ of the total time. Most of the time was spent on the repair of the lifting mechanism and the excavator travel mechanism, $25 \%$ and $30 \%$ of the time spent on the repair of mechanical equipment, respectively. $14 \%$ and $16 \%$ of the time spent on the repair of mechanical equipment was spent on the repair of the swing mechanism and the pressure mechanism.

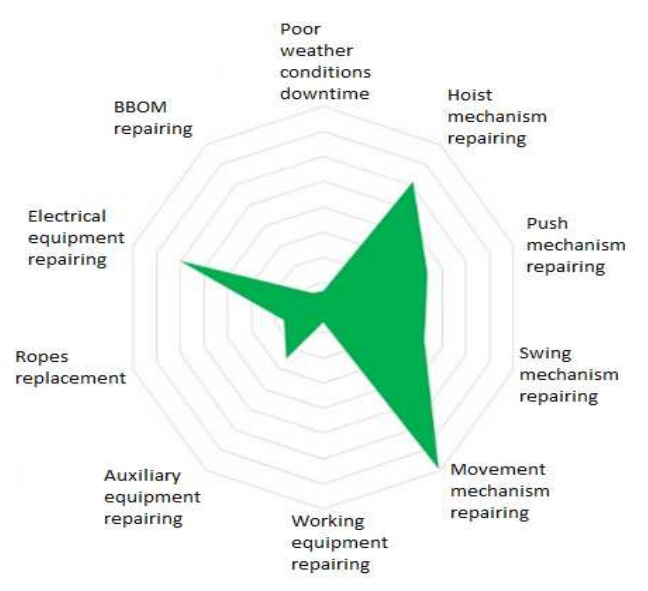

Fig. 4. Distribution of downtime of the Mining excavator per year [7].

To reduce sudden failures, it is advisable to analyze in detail the causes of ad hoc shutdowns. 
One of the ways to solve the problem of reliability of mining excavators is to improve the maintainability of excavators, improve their adaptability to maintenance and repair [11].

The successful operation of a mining enterprise depends not only on the innovative potential and technical equipment, but also on the qualifications of the personnel. The qualification of the driver greatly affects the performance of the excavator and the level of operational reliability of the machines [15].

According to the requirement of the operating manual for mining excavators of large unit capacity, which include machines with a bucket capacity of more than $15 \mathrm{~m}^{3}$, the excavator operator must have at least 5 years of experience in operating such equipment.

There are several methods for assessing the skill level of an excavator operator. For example, in the works of P.I. Koch proposed to evaluate the quality of the driver's work by the control coefficient determined as follows [16]:

$$
k_{y}=T_{T} / T_{f},
$$

where $T_{T}$ is the theoretical time of the excavation cycle, $\mathrm{s} ; T_{f}$ is the actual time of the excavation cycle, $\mathrm{s}$.

N.G. Dombrovsky proposes to use the coefficient $\mathrm{km}$ as a criterion for assessing the skill level of a driver, defined as the ratio of the actual (operational) and technical performance of the excavator [17]:

$$
k_{M}=Q_{f} / Q_{T}
$$

where $Q_{f}$ is the actual performance of the excavator, $\mathrm{m}^{3} / \mathrm{h} ; Q_{m}$ - technical productivity of the machine, $\mathrm{m}^{3} / \mathrm{h}$.

Accepted by N.G. Dombrowski's qualification, the assessment criterion more fully characterizes the work of an excavator driver.

\section{Conclusions}

Thus, the listed factors lead to the destruction of parts of mining excavators.

The rate of resource consumption of a mining excavator depends on the correct choice of the strategy and maintenance system, the correctness of the regulatory framework and the quality of routine maintenance by qualified personnel. A properly formed structure and value of the parameters of the repair cycle of a mining excavator can reduce the intensity of its resource consumption and increase its service life.

The structure of the repair cycle should be adjusted taking into account the natural aging of the excavator and factors: natural and climatic, mining and geological, quality of face preparation, excavator control, organizational factor, as well as the maintenance strategy. The impact of external conditions and natural processes occurring during the operation of mining machines is proposed to be assessed using the appropriate degradation factors.

\section{References}

1. K.N. Trubetskoy, M.V. Rylnikova Gorny informatsionno-analiticheskiy bulletin, 21-32, (2015)

2. R. Yu. Poderny Gorny Information-Analytical Bulletin, 2, 148-167 (2015).

3. A.V. Mikhailov et al, IOP Conf. Ser.: Earth Environ. $\quad$ Sci. $\mathbf{8 7}$ 022014, (2017) doi :10.1088/1755-1315/87/2/022014

4. S.A. Konopelko Mining Industry 3 (103) May June, 8 (2012).

5. D.A. Shibanov, S.L. Ivanov, D.A. Chishegorov Technological equipment for the mining and oil and gas industry. Collection of works of the XVIII international scientific and technical conference "Readings in memory of V. R. Kubachek", Ekaterinburg, p. 266-269, (2020).

6. K. Anistratov, T. Donchenko, D. Shibanov World Coal, 27(7), 45-47, (2018)

7. P.V. Ivanova, S.A. Asonov, S.L Ivanov., S.Yu Kuvshinkin. Mining information and analytical bulletin, 7, 52, (2017).

8. D.A. Chishegorov, D.A. Shibanov Problems of development of deposits of hydrocarbon and ore minerals, 1, 305-311, (2020)

9. E.V. Pumpur et al. Mining information and analytical bulletin, 12 (special issue 41), 3-19, (2019) DOI: 10.25018 / 0236-1493-2019-12-413-19.

10. V.E. Kvaginidze, Ya.M. Radkevich, V.I. Rusikhin, Repair manufacturability of metal structures of open-pit mechanical shovels in coal mines of the North (Moscow. MSTU. 1997)

11. V.S. Kvaginidze Proceedings of the scientificpractical seminar "Physical and technical problems 35 of the development of the South Yakut region", Neryungri, NF YSU, 214-217, (1998)

12. G. Zwengelstein Maintenance based on reliability. Practical guide to the application of RCM, (Editions Hermès, Paris 1996).

13. S.N. Zharikov Zapiski Gornogo Instituta. 229, 56-61, (2018) DOI: 10.25515/PMI.2018.1.56

14. P. V. Ivanova, S. L. Ivanov "Mining in the XXI century: technology, science, education: Abstracts. (Saint Petersburg mining university "Gorny", 2015).

15. A.A. Abdrakhmanov, G.G. Safin, I.A. Gabitov Modern science-intensive technologies. 12-2, 193-198, (2015)

16. P.I. Koch, Reliability of mechanical equipment of open pits (Moscow: Nedra, 1978).

17. N.G. Dombrovsky Excavators: general questions of theory, design, research and application. (Moscow: Mashinostroenie, 1969).

18. Abdelwahab Agaguena, A. V. Mikhailov collection of works of the 79th International Scientific and Technical Conference, Magnitogorsk 2021. Actual problems of modern science, technology and education. p.46. (2021) 